Popular Music

http://journals.cambridge.org/PMU

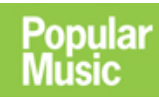

Additional services for Popular Music:

Email alerts: $\underline{\text { Click here }}$

Subscriptions: Click here

Commercial reprints: $\underline{\text { Click here }}$

Terms of use : $\underline{\text { Click here }}$

\title{
Popular music and the aesthetics of ageing
}

Andy Bennett and Jodie Taylor

Popular Music / Volume 31 / Special Issue 02 / May 2012, pp 231 - 243

DOI: 10.1017/S0261143012000013, Published online: 23 April 2012

Link to this article: http://journals.cambridge.org/abstract_S0261143012000013

How to cite this article:

Andy Bennett and Jodie Taylor (2012). Popular music and the aesthetics of ageing. Popular Music,31, pp 231-243 doi:10.1017/S0261143012000013

Request Permissions : $\underline{\text { Click here }}$ 


\title{
Popular music and the aesthetics of ageing
}

\author{
ANDY BENNETT and JODIE TAYLOR \\ Griffith Centre for Cultural Research, Griffith University, 170 Kessels Road, Nathan, Qld 4111, Australia \\ E-mail: a.bennett@griffith.edu.au; jodie.taylor@griffith.edu.au
}

\begin{abstract}
The cultural turn in sociology and related fields of study has brought with it new understandings of the various ways social identities are formed. In a post-structural landscape, social identities must increasingly be regarded as reflexively derived 'performative assemblages' that incorporate elements of the local vernacular and global popular cultures. Building on the above reinterpretation of social identity, this paper takes as its central premise the notion that, in addition to its well-mapped cultural importance for youth, popular music retains a critical currency for the ageing audience as a key cultural resource of post-youth identification, lifestyle and associated cultural practices. In its examination of the relationship between popular music, ageing and identity, this paper uses illustrative examples drawn from ethnographic data collected by the authors between 2002 and 2009 in Australia and the UK.
\end{abstract}

\section{Introduction}

It has long been held that the concept of ageing, as with other aspects of social being, is a construct that 'reflect[s] the beliefs and values found in a specific culture at a particular period in history' (Featherstone and Hepworth 1995, pp. 30-31). In the context of developed, westernised societies, a key issue of debate has been the extent to which the process of modernity, particularly the transition to late modernity, has itself influenced the nature of social identity as a whole. This debate has been punctuated by the cultural turn in contemporary social theory (see Chaney 1994) which places increasing emphasis on the necessity of regarding identity as a reflexively derived, 'creative' project of the self (Giddens 1991; Stevenson 1995). Underpinning this argument is the observation that, with the shift from production to consumerbased societies, there has been a concomitant increase in individuals' leisure time and provision of cultural resources (Lull 1995; Chaney 1996). In this late modern social context, identities are argued to be the product of the everyday appropriation and re-inscription of mass-produced cultural resources with new meanings drawn from localised experiences. This, it is contended, also provides a basis through which individuals are able to create individual and collectively articulated 'lifestyles' (Chaney 1996). It follows then that ageing identities and lifestyles are also reflexive constructs that draw on and symbolically transform available images, objects and texts, including music. 
The relationship between popular music and ageing continues to be a relatively thinly mapped field in popular music studies and cognate fields of research. This is in stark contrast to work on youth which, at least in a post-1955 context, has provided a key focus for researchers in interpreting the cultural significance of popular music (see, for example, Chambers 1985; Bennett 2000). As a small number of recent studies have begun to illustrate, however, the concept of youth culture is itself becoming increasingly problematic as once clearly demarcated youth cultures and music scenes become increasingly multi-generational (Kotarba 2002; Bennett 2006; Smith 2009; Taylor 2010). The findings of these studies suggest a crucial need for scholarship that addresses the cultural importance of popular music for ageing, post-youth audiences. This article will critically examine the everyday significance of popular music in offering up a series of cultural resources - visual, textual and sonic - that combine into sociocultural texts underpinning the production and articulation of ageing identities among baby-boomers and post-boomers. ${ }^{1}$ The article takes as its central premise the notion that popular music retains a critical currency for ageing audiences as a key operative modality of identity, lifestyle and associated cultural practices.

\section{The production of ageing through musical taste}

Sociological studies of musical taste, participation and ageing often suggest that, for a large proportion of ageing subjects, musical tastes narrow and an investment in popular music activities commonly lessens as one ages (Holbrook and Schindler 1989). Data presented in Coulangeon and Lemel's (2007) study of omnivorous musical taste in France shows that, as one ages, one's musical tastes generally become more homologous. As we may expect, genres like techno, rap and rock, typically associated with youth culture and consumption, become least favoured. In Harrison and Ryan's (2010) detailed analysis of cross-sectional survey data on the life-course trajectory of musical taste, it was noted how people's taste in music commonly increases from youth to middle age, ${ }^{2}$ declining from middle age onwards into later life. Moreover, what middle-aged and older people commonly liked did not include those musics that had strong youth appeal. One explanation, among others, for why this may be so, proffered by Harrison and Ryan, considered the effects of ageing and social stigma: 'an affinity for certain genres can become in essence anti-cultural capital because it conflicts with normative expectations of "age-appropriate" behaviour' (Harrison and Ryan 2010, p. 665, emphasis in original). In other words, for subjects to be perceived as ageing successfully, they must demonstrate - through taste - a significant distance from both contemporary youth and from the self of youth. Our major criticism of literatures such as these is the lack of attention they give to music's embeddedness in everyday cultural practices, where music tastes and extra-musical style may manifest in a variety of other ways through films, fashion and visual arts for example - and cannot be so easily limited to more blatant measurements like listening to the radio or going to a concert.

Other literatures around music and the production of ageing that warrant mentioning here are those that emerge from music therapy and social psychologies. Music's function as a therapeutic tool is well examined, especially in relation to its ability to facilitate social interaction in older people with dementia and Alzheimer's disease (see, for example, Koger et al. 1999). However, as Hays and Minichiello (2005) point out, we actually know very little about the ways healthy 
and independent ageing subjects use music in their everyday lives. While they attempt to unpack this with some success, arguing favourably for music's role in negotiating identity and self-understanding, constructing meaning, connecting oneself with past events, facilitating spirituality, experiencing beauty and maintaining wellbeing, they fail to discuss the specificities of musical taste, genre and extramusical style, focusing instead on music as a singular phenomenon. Therefore, while we broadly understand music's continuing significance in the lives of older people and the ways that music continues to contribute to the health and wellbeing of the ageing subject, a question remains, however; what forms of popular music do ageing subjects use to aestheticise their subjectivity - that is, in the performance of their ageing identity - and, through this, what types of scenic relationships do ageing subjects maintain?

While it would be unfair to suggest that popular music studies has been wholly ignorant of the need for a form of address that engages with popular music's aesthetic value in a post-youth context, taking this forward in a way that constructively deals with audience clusters has been a rather different matter. For example, in her otherwise instructive reading of heavy metal culture, Weinstein refers to ageing heavy metal audiences thus: 'Once part of the metal subculture, they are now like wistful emigrants, living a continent away in another world than their own' (Weinstein 2000, p. 111). Similarly, Thornton (1995, pp. 101-3) argues that older people's continuing investment in dance club and other music-based scenes amounts to a resistance towards social ageing. In both of these well-documented observations, there seems to be the nagging assertion that ageing audiences' continuing investment in popular music, in anything other than a private sphere context, can only be understood via a need to 'reject' ageing through absorption in a 'youth' cultural environment within which they are increasingly out of place and redundant. Arguably, however, such assertions are both grounded in a relatively essentialist notion of 'ageing' and take little consideration of the ways in which the aesthetic properties of popular music, and the latter's value in facilitating the production and expression of lifestyle identity politics, may effectively change over the life-course.

The work of DeNora has perhaps gone closest towards investigating the shifting dynamics underpinning the relationship between music and biographical trajectory. For DeNora, music's key capacity in this respect is its role in the production of the self over the life-course: 'In this sense, the past, musically conjured, is a reflexive movement from present to future, the moment-to-moment production of agency in real time' (DeNora 2000, p. 66). Through positioning music as embedded in memory and embodied through a continuous process of reflection, DeNora illustrates how music becomes an important source of self-mapping for the ageing individual. In this way, individuals effectively produce and position themselves as ageing subjects in a context of everyday experience that extends within and across, for example, relationships, careers, families, and so on. In each of these and other everyday contexts, the presence of particular musical texts in the memoryscape resonates with their ongoing presence in the everyday soundscapes of the here and now. As such, musical experience resonates strongly with the broader phenomenological, sensual and aesthetic experiences of growing older.

DeNora's reading of individuals as actively producing themselves over time with and through music is a critical starting point in beginning to understand the complex juxtaposition of ageing, music and lifestyle in a late modern context. However, such a process of production is, in itself, inextricably linked with highly 
particularised forms of everyday experience generated through the interface of macro-global culture with the mundane culture of the locally specific. Again, existing work in the field of music sociology and popular music studies has established important points of reference for understanding the production of musicalised identities that draw on both local and global points of reference. For example, Bennett and Peterson (2004) demonstrate how the everyday aesthetic production of music scenes is managed amid a complex interplay of local and global resources, with scene-based relationships crystallising across three distinct, yet interrelated, terrains - local, translocal and virtual. It follows that the production and management of ageing identities similarly corresponds with particular patterns of musical taste, style and arrangements governing scene gatherings and behaviour as these manifest themselves in specific local, trans-local and virtual contexts. Combined with the impulse of specific genre manifestations and their historical referents, such musicalised mobilisations of the ageing identity often embody distinctive manifestations of cultural politics in which forms of scenic competence, authority and even authorship are often strongly punctuated.

Where certain consumptive patterns mark age as successful or appropriate, others may mark age 'inappropriately'. Here, emphasising the postmodern fluidity of identities, performance and reflexive agency, we will now explore those productions of ageing constructed in relation to scene affiliations that do not diminish with age and therefore, within a normative context, may be deemed 'age inappropriate'. Specifically, we will explore the practices and subjectivities of ageing dance music enthusiasts from a local queer scene in Brisbane, Australia and ageing punk rock fans in East Kent, UK. We dispense with the logic of what may or may not be appropriate musically mediated ageing to examine the complexities of scene participation in relation to subjective constructions of an ageing that is self-aestheticised through popular music activities. Thus, we argue that popular music can retain critical currency for ageing subjects, allowing them to modulate their performance of age to incorporate the cultural practices of their chosen lifestyle.

\section{Dance music and ageing queers}

Identities - gender, sexual, racial, ethnic - may be thought of as performative in the sense that they are constructed through the repetition of norms that precede and exceed the performing subject (Butler 1993). Yet, as we argued earlier, it would appear that age remains highly essentialised and corporeally bound, where the expectations placed upon how one is to behave corresponds with the number of years they have been alive and the tell-tale physical signs of time passed. Post-youth investment in popular music and associated scene activities noticeably troubles the normalisation of ageing identities, where certain types of scene activities often amount to what may be perceived as an improper performance of one's age (Taylor 2010). From middle age onwards, it is expected that one's consumptive practices, tastes and concerns 'mature', thus becoming more attuned to the normative foci of a post-youth life-course - work, parenting, community, retirement, and the like. This is not to say that social participation in music-related activities is assumed to cease altogether, but that the nature of the music-related activities in which postyouth subjects invest time and energy is expected to change to reflect their ageing subjectivity. For example: in accordance with the logic of normative, and thus 
'respectable', ageing in a white, Western, heterosexual, working-class/middle-class context, it is likely to be regarded as commonplace or proper for someone in their forties, fifties, sixties or beyond to invest time in choral singing, perhaps, or to spend the occasional Saturday night dancing to their favourite crooner at the local services club or community centre. It is far less common, and by extension less acceptable, for the same ageing subjects to spend their Saturday nights dancing to progressive trance at a nightclub.

In this section, we examine ageing subjects in the context of a queer dance music scene by drawing on interview data and participant observations taken from a larger project currently in development which examines a broader range of queer music scene activities in local and trans-local contexts (see Taylor 2008, 2010). ${ }^{3}$ The material presented here, however, draws specifically on interview data from eight tape-recorded and transcribed interviews and extensive field notes gathered in queer club spaces and dance parties between March 2009 and February 2011.4 The interviews represent a sample of eight middle-aged scene participants from Brisbane, four women and four men, aged between 40 and 50 who, as post-youth subjects, continue to participate in queer club culture in a variety of ways, ranging from regular event attendance to event organisation and DJing. For those who run events and/or DJ at them, this is a hobby and not a profession, as all had full-time employment across a variety of fields including health work, academia, retail, business and information technology. None of the interviewees were primary carers of children, this being typical of the scene at large.

In the 20th and 21st centuries, bars and nightclubs have functioned as the most common and socially visible spaces in which queer scenes have congregated. Since the early 1970s, dance music genres like disco, garage and house have been intrinsically linked to Western gay male cultures in particular (see, for example, Hughes 1994; Currid 1995; Buckland 2002). Today, these and a range of other contemporary electronic dance music (EDM) genres such as electro, techno and trance (and a myriad of subgenres) can be heard in queer clubs around the world. As such, music and dancing are integral to public queer lifestyles and, perhaps more than any other musical genre, queer cultures have been most closely identified with dance music forms. For generations of people who belong to a stigmatised gender and/or sexual minority, dance music has provided a backdrop for establishing and maintaining a queer public sphere in which their gender and sexual identities can be more freely negotiated and performed and it appears that this can remain true for some participants as they age.

In the club spaces and dance parties observed, the styles of EDM played were quite varied, ranging from minimal techno to commercial/progressive house, trance and remixed retro disco tracks. It is also quite common for DJs to draw on remixed versions of funk, commercial pop, darkwave and indie/punk in their sets. The range of artists that one is likely to hear during the course of a night might include American house group Deee-lite, British electro group Underworld, Canadian electroclash artist Peaches, American dance-punk band Gossip, French electropop artist Miss Kitten, Italian electrohouse producer Benny Benassi or British progressive house duo Leftfield. However, club attendees appear to have less of an attachment for a specific artist or EDM producer, instead favouring the styles of local DJs and particular themed club nights. For when I discussed music with my interviewees they generally referred to liking the style of DJ X or DJ Y based on broad stylistic traits such as DJ X's dark and tribal feel or DJ Y's groovy funk/disco sets. 
Among the middle-aged subjects interviewed, all bar one began their involvement with queer club scenes around the time they 'came out'. ${ }^{5}$ For some this was in their late teens, while for others it was in their late twenties. For one woman, however, her scenic involvement did not begin until she separated from her husband during her mid-thirties. In youth and early adulthood, the regularity of participation was quite high, with respondents reporting club or dance party attendance at least once a fortnight and up to three times a week. Now in middle age, all respondents acknowledged a partial decline in the frequency of club attendance and associated activities such as alcohol consumption and recreational drug use, ${ }^{6}$ speculating that these now occur, on average, at monthly or bimonthly intervals for the majority of them. For Jemima (aged 40) and Sarah (aged 47), the reasons for decline in participation were more to do with physical injury than with a lack of desire for participation. One experienced severe back pain due to injuries sustained in early adulthood while the other had to manage a brain injury sustained in later life that decreased her mobility quite dramatically. However, said Jemima, 'I'm really into dance culture and DJ music ... and um, well I probably don't go out as much as I used to when I was younger, but I go out to dance to music more than anything else'. The reasons others gave for their decline in attendance varied between individuals but included: a noticeable increase in physical recovery time post-party; career demands; boredom with regular 'commercial' events, preferring instead the niche semi-regular independent events; and, for one woman, her continued unsuccessful attempts at becoming pregnant. While for all respondents ageing caused some changes in the degree and types of participation in club culture, all respondents stipulated their intentions to remain participating in the scene in similar ways for as long as physically possible: 'I don't kid myself that I'll be 85 and on the dance floor, but while I'm still able-bodied and while my body still tolerates the chemicals [drugs], I'll still be into it,' said Roger (aged 41). Similarly, Emily (aged 40) commented, in reference to herself and her female partner (Lucy, aged 45):

We think that we'll always dance somewhere, somehow ... I think we'll always be going out clubbing and I don't think we'll end up with that typical un-producted lesbian hair and jeans and collared shirts 'cause that's not what we're like and I think we'll always be quirky bent weirdos. ... I think we'll always like to go to events, but my prediction is that it will be less club, like full on type stuff and more, but then who knows, we could be doing club stuff when we're 60 or even 70 .

Based on our interview data and confirmed through general conversations in the field, ageing scene participants demonstrated only moderate concern for, and consciousness surrounding, external perceptions of their ageing subjectivities. Almost all of my interviewees situated themselves as 'outsiders' to the 'mainstream' which they perceived as granting them some immunity from judgement and expectation. 'By being queer quirky or whatever we've already discounted that and we already don't fit into that box', said Emily. In conjunction with being queer, all interviewees also noted that with age too comes a certain freedom of self-expression. ' $\mathrm{I}$ ' $\mathrm{m}$ older and I'm a bit more confident [and] I don't care what people think so much anymore', said Tex (aged 44). In their discussions of ageing within the scene, the majority of respondents directly linked to the ideologies and politics of being queer to a more fluid, unrestricted and individually created sense of self-presentation in middle age. Jemima said that she thought perceptions of ageing were not so acute in the 'queer world'. 'We're a bit edgier and groovier for some reason ... and hang on to [our] 
individual quirkiness or that individual stance in [our] appearance or what [we're] involved in much later in life.' Tex commented that in his experiences, queer clubs accommodate a range of visual styles taken up by people of various ages because 'queer is an alternative culture' and the politics of queer are more 'lefty'. Similarly, Emily commented:

I think the straighter the environment, like 'straight' in inverted commas, so not necessarily heterosexual, but straight thinking ... you know, the quirky bent end versus the straight conservative end, I think the straighter you are, the more you age, the faster you age and the more judgments that are placed on you.

For Emily, Jacob (aged 43) and Patrick (aged 50), growing older and maintaining scene involvement gives them licence to behave in ways that may appear scandalous to scene outsiders. 'With age, we're not motivated anymore by what other people think is important or by how people think we "should" behave', said Emily. A continued sense of association with the scene was dependent upon attendance at scene-specific dance parties which acted as the primary way in which participants would come together and collectively perform their queerness through music, dancing, costuming and sanctioned displays of queer affections. From observations and discussions, dance parties provided an 'identity performance space' in which a range of sexual encounters, outrageous costuming and non-normative gender performances were both sanctioned and largely encouraged. For Jacob, being in the scene normalised his 'obsession with dancing', as he put it, as well as his drug use, sexual promiscuity and playful cross-dressing, all of which is kept hidden from family and work colleagues in his daily life. Similarly, for Patrick the club space gave him a chance to connect with friends from the leather community and other queer communities at the same time and to embrace his leather persona in a context outside of a regular sex club or gay male leather gathering. None felt that their ageing subjectivities were problematic in the context of their current forms of scene participation, and four of them explicitly mentioned that they get credit for 'being cool' from younger scene members. Recalling his own experiences as a young person in the scene, Jacob said that he does not believe age is a big issue in the queer scene he participates in:

No, there's not as much ageism in the queer scene ... Like for example in BDSM spaces there's sort of a recognition of experience, like that it's useful in some way, so age doesn't seem to be a problem in that sense 'cause it's part of it ... When I was young, well, I remember thinking that older people were interesting as opposed to, get fucked, or get out of my way or I'm just going to ignore you, I just find that response a really strange thing in people that they would dismiss old people. I know some of my best friends and mentors were people older than me. I got a lot of value out of those people ... I think it's always possible for people to celebrate it [ageing] more. But I actually do think it's dealt with more positively outside of the more mainstream gay scene if you like. And again, that's probably a bit of a generalisation too because I know that there have always been ageing people in gay clubs and there would be a level of don't care or maybe they do care, or maybe there's a level of comfort for a lot of ageing people in those spaces.

Continuing to engage in dynamic processes of identification, all of the respondents involved in this aspect of the research demonstrated an aesthetic commitment to their ageing queer identities through dance music, style and scene participation. Here then, it can be said that scene participation mobilises collective physical embodiment of their queer identity and gives participants a context and structure for 
continued performances of both their sexual and musical identities as they age. While the majority of sociological and popular music literatures to date have argued that it is common for middle-aged and older subjects to discard the music and scene-based identities of their youth and/or cease engaging with new musical forms, it cannot be considered an exclusive outcome of the ageing process. In contrast to the literature on dance club cultures which situate youth as not only a central but almost an exclusive condition of participation (see, for example, Thornton 1995; Malbon 1999), these individuals have reinterpreted dance club conventions so as to accommodate queerspecific post-youth identities, sensibilities and cultural practices. Dance music is thus central to their queer lifestyle project and functions centrally in the maintenance of a queer middle-aged aesthetic.

Like Kotarba's (2002) study of ageing rock ' $n$ ' roll fans and Smith's (2009) account of an ageing Northern Soul scene from Britain, the participants of the queer scene which we have examined can be said to incorporate the values, tastes and sensitivities of their youth into the ever more complex everyday subjectivities of adulthood. Moreover, like Hodkinson's (2011) recent work on ageing goths who, he concluded, were 'far from being isolated within a subculture dominated by youth, or fixated on a desperate attempt to retain their own adolescence' (Hodkinson 2011, p. 281), the majority of my interviewees all made reference to the scene ageing with them. As Patrick so succinctly remarked: 'we change, venues come and go, the scene changes, dance music changes, everything is always changing so there's no point in holding onto the past'. These studies demonstrate the various ways in which scene participation, music fandom and ageing subjectivities can be reconciled so as to create a space in adulthood for typically youthful musical identity articulations. Moreover, collectively, this work also points to the fact that across multiple genres of expression, ageing identities can be aestheticised through popular music activities, tastes and consumption. In order to further consider these issues, we will now shift our focus towards ageing in the context of punk audiences.

\section{Ageing punks}

Just as the urban queer scene setting described above produced a particular kind of context within which ageing identities were constructed and articulated, so the punk scene in East Kent produced its own set of interpersonal dynamics and cultural discourses of ageing. The research on this scene involved interviews with some 15 ageing punks between the ages of 42 and 55.7 Most of the interviewees were from working-class backgrounds, although one had attended university. All of the interviewees were male. Indeed, the local ageing punk scene was itself predominantly male. None of the ageing punks interviewed was married to or lived with ageing female punks, nor were wives or partners present at gigs attended as part of the research. When questioned on the issue of gender among ageing punk fans, many interviewees said that other ageing punk fans they personally knew tended to be male. On one occasion Stu, an ageing male punk interviewee, offered to arrange a follow-on interview with an ageing female punk friend of his but this never transpired. Similarly, repeated attempts to secure an interview with an ageing female punk recommended by Ned, another research respondent, were also unsuccessful. To some degree, the absence of female involvement may be attributable to the nature 
of the scene itself. Although not stridently opposed to female involvement, discourses of male bonding and a mistrust of women, similar to those identified by Cohen (1991) in her study of male, working-class local musicians in Liverpool, were evident among interviewees throughout the research.

Nonetheless, the ageing punk scene in East Kent offers a series of significant insights regarding the production of ageing in the context of a musical genre and accompanying stylistic and political affiliations that were once considered so staunchly associated with youth (see, for example, Hebdige 1979; Chambers 1985). Spread out over a wide area of provincial towns and rural locations, sporadic punk performances in this region act as nodal points for the assembling of ageing punks, whose continuing sense of association with punk appears to be closely linked with both maintaining of face-to-face contact and listening to punk music, ranging from old-school punk to more recent styles such as ska-punk and punk-metal fusion. The emphasis upon face-to face contact is in contrast to some other examples of ageing music scenes where a sense of scene association is primarily articulated through trans-local gatherings, such as festivals, and the forms of virtual association afforded by the internet (see Bennett and Peterson 2004). Moreover, unlike the observations of Andes (1998) regarding the practical obstacles to remaining punk beyond the age of 30, the ageing punks in East Kent saw little in the way of obstacles, physical, aesthetic or otherwise, to their continuing association with punk. Indeed, in discussing what it meant to be a punk in, or approaching, middle age, many interviewees were generally at pains to point out the positive differences they perceived between their former youth identification with punk and their post-youth punk affiliation. For example, Jason, a 55-year-old punk, noted how as a teenager he had been motivated by the references to anarchy in late 1970s punk songs by artists such as the Sex Pistols, but now felt that such references were overly romanticised. Similarly, Ned, a punk in his mid-forties, observed:

I think when you're a teenager, it's a bit frustrating because you want to change the whole world and you want to change it right now and you want everything to be good, the way you see good as being. And it makes you angry that you haven't really got any power to do anything about it. And as you get older you do maintain your idealism but you get a bit more sensible about what kind of impact you can have yourself, and [realise] that things take a long time to change, and that it's not possible to change everything at once. But, as long as you act right in your life and do the things that you can which will influence the people around you, then you're doing the best that you can so you're a lot less angry about things.

Although often self-critical of their earlier punk selves, Jason, Ned and some other interviewees were at the same time adamant that, from the outset, punk had instilled within them a life-changing experience for the better. Ageing punks commonly suggested that punk had played an important part in their transition from youth to adulthood, providing them with a street-wise outlook and a sense of realism. Many intimated that their path to becoming what they perceived as fully rounded, critically aware individuals dated in considerable part from their initial involvement with punk and their internalisation of the punk ethic. Moreover, notwithstanding the critical re-evaluation of their punk identity over time, many older punks suggested that their basic sense of self continued to be informed by the punk ideology. Indeed, a number of interviewees considered themselves to be the very essence of a 'punk personality', as illustrated in the following extract from an interview with Stu, an English punk in his early fifties: 
There's still a part of me that embraces the rebelliousness, the sort of ehm, 'stick your two fingers up at the establishment', the sort of political nature of it, the fact that 'yeah this is what I like, an', therefore, why can't I do it?' ... [Punk] was a pivotal part of my life that has influenced everything since ... my musical influences, an' the way I think about things ... I can actually chart it back to a certain period where, eh, $\mathrm{y}^{\prime} \mathrm{know}$ things suddenly became different. And because you're different and, $\mathrm{y}^{\prime} \mathrm{know}$, the rest of society sees that difference as bad [it] has an influence. An' you realise, well, 'maybe [pauses] everything's not as bad as it seems, or as people portray it', an' it gives you a sort of outsider feel.

Such an 'outsider feel', and its personification in the 'timeless lyrics' (a phrase used by Stu) of British punk bands such as The Clash and the UK Subs, was related on various occasions by ageing punks, particularly when seeking to describe how their view of the world often appeared so diametrically opposed to others of their own age. References to viewing the world from a 'punk perspective' were numerous in conversations ranging from politics, racism and terrorism to work and career. In all such instances, ready associations were made between 'lessons learned from punk' and current, personal outlook. For example, one ageing punk, Jim, had elected to work with the homeless, a job which he said, despite its relatively low salary, low status and limited promotion prospects, afforded him the satisfaction that he was doing something positive to try and 'fix a big problem that the inequalities of the capitalist system has produced'. Similarly, Steve, a punk in his late forties observed:

I have never really worked in the straight world, I've always been outside it doing other things. Whether that be ... making money from putting on a few gigs, or buying and selling stuff on the internet, or this sort of stuff ... I've had two straight jobs in 26 years, and all I can remember is complete resentment to[wards] having to be somewhere for eight hours, when I can think of loads of things to do! ... I often think that work is the last vestige of the unimaginative ... to this day, I still want to make money outside of all that. I just think, at the end of the day, that it's the only way that you can maintain control over what you're doing.

A common thread running through the above accounts is the way in which the ageing punks concerned have creatively evolved various means of maintaining a DIY (do-it-yourself) punk aesthetic into middle age. Indeed, all of the ageing punks cited above noted how the anarchic energy that they had identified with punk as teenagers had transformed into a more mature and studied lifestyle project over the years. In the long term, what these people appear to have taken from punk are a series of resources through which to reproduce themselves as individuals over time. Rather than seeing punk as a lifestyle project associated with the temporal limitations of physical youth-hood, the individuals discussed above consider punk as an inseparable aspect of their basic selves. While their ageing bodies have transcended conventional discourses of punk as bound up with youth-based resistance, these individuals have reworked and refined such discourses to bespeak a new, postyouth series of punk-centred sensibilities and cultural practices.

\section{Conclusion: ageing in popular music contexts}

The case studies of ageing punks and ageing queer dance music enthusiasts presented here have provided two locally and musically distinct examples within which ageing subjectivities may be read in the context of scene-specific musical involvement to produce particular forms of 'youthful' selfhood for the post-youth subject. In contrast to much of the literature on music and ageing, these cases 
suggest that supposedly 'youthful' genres such as punk and dance music can retain meaning in middle age, pointing to the variety of possible aestheticised modalities of ageing that are mediated through popular musics. Furthermore, both cases problematise perceptions of ageing in scene contexts that equate ageing with scenic redundancy and negatively infer continued involvement as signalling a refusal to 'grow-up'.

While all punks and queers interviewed above noted that as they aged the nature of their scene participation has changed slightly, complete scene withdrawal did not figure into their visions of ageing. Rather, interviewees demonstrated how ageing and scene participation could be synthesised, producing an effect on both the conditions and expectations of middle age and the capacity for the respective scenes to accommodate ageing subjects. Both scenes demonstrated little concern for the physical obstacles and/or external perceptions that impede post-youth scene participation. For both the queers and punks interviewed here, an investment in scene-based ideologies meant that participants already saw themselves as 'different' or 'outsiders'. It followed, then, that ageing as part of a punk or queer scene instilled within them a sense of distinction that afforded them alternative visions of the future and gave them greater capacity to resist the normative modalities of ageing.

In this article, we have discussed two unique ways in which scenic identities, lifestyles and practices can not only be carried into middle age but also produce alternative versions of middle-aged identification and lifestyle. From this, it is fair to conclude that post-youth investments in popular music scenes have the potential to effectuate a range of ageing subjectivities: subjectivities that achieve distinction through processes of aestheticisation that are directly related to the subjects' scene context. Where identities are reflexively derived and performatively assembled, popular music scene involvement, therefore, plays a significant role in the aestheticisation of ageing. In making these claims we remain fully aware that much will be contingent upon other socio-cultural identifiers such as ethnicity and/or geographical location which may have a significant effect on one's ability to access scene contexts. We also acknowledge that the more spectacular nature of the scene examples discussed potentially create more spectacular performances of ageing identities. As such, further investigation into post-youth scene-based identification in non-white, Western contexts and across a more diverse range of music genres is necessary to create a more comprehensive mapping of the cultural intersections between popular musical investments and ageing subjectivities.

\section{Endnotes}

1. In a Western cultural context, the term 'babyboomer' refers to the generation of people who grew up in the 1960s and 1970s and were born in the period after World War II. Therefore, 'post baby-boomer' refers generically to the generation that followed.

2. In sociological terms, it is commonly accepted that 'youth' refers to the time between childhood and adulthood (approximately between 15 and 25 years) and 'middle age' refers to the time after young adulthood and before old age (approximately between 40 and 65 years). It

is this understanding that we employ in this study.

3. The larger project draws on Taylor's doctoral research undertaken in Australia and her postdoctoral research conducted in Berlin, Germany. This work will form the basis of a book project entitled Playing it Queer: Popular Music, Identity and Queer World-making which will be published by Peter Lang in 2012.

4. Due to the limitations of this article, only eight interviews are being directly referenced here; however, these interviews can be considered 
indicative of the numerous conversations around ageing participation held with other participants while in the field. All personal information included here is with the respondents' consent and pseudonyms have been used to protect their identities. All interviews were conducted in Brisbane on the following dates: Jacob, 15 March 2009; Tex, 25 March 2009; Roger, 30 March 2009; Emily and Lucy, 31 March 2009; Jemima, 21 April 2009; Sarah and Patrick, 5 February 2011.

5. 'Coming out' is a process of disclosing one's sexual and/or gendered non-normativity to friends and family.

6. All respondents admitted that they continue to use recreational drugs on occasions. The drugs most commonly cited were ecstasy (methylenedioxymethamphetamine), speed (amphetamine), acid (lysergic acid diethylamide) and marijuana.

7. Due to the limitations of this article, only five interviews are being directly referenced here; however, as with the foregoing section on the ageing queer scene in Brisbane, the cited interviews with ageing punks are broadly representative of the various interviews conducted with other participants while in the field. All personal information included here is with the respondents' verbal consent and pseudonyms have been used to protect their identities. All interviews were conducted in East Kent, England on the following dates: Jason, 15 December 2002; Ned, 1 March 2003; Stu, 2 May 2003; Jim, 1 Feb 2004; Steve, 6 June 2004.

\section{References}

Andes, L. 1998. 'Growing up punk: meaning and commitment careers in a contemporary youth subculture', in Youth Culture: Identity in a Postmodern World, ed. J.S. Epstein (Malden, Blackwell), pp. 212-31

Bennett, A. 2000. Popular Music and Youth Culture: Music, Identity and Place (London, Macmillan)

Bennett, A. 2006. 'Punk's not dead: the continuing significance of punk rock for an older generation of fans', Sociology, 40/2, pp. 219-34

Bennett A., and Peterson R.A. (ed.) 2004. Music Scenes: Local, Translocal, and Virtual (Nashville, Vanderbilt)

Buckland, F. 2002. The Impossible Dance: Club Culture and Queer World-making (Middletown, Wesleyan University Press)

Butler, J. 1993. Bodies that Matter: On the Discursive Limits of Sex (New York, Routledge)

Chambers, I. 1985. Urban Rhythms: Pop Music and Popular Culture (London, Macmillan)

Chaney, D. 1994. The Cultural Turn: Scene Setting Essays on Contemporary Cultural History (London, Routledge)

Chaney, D. 1996. Lifestyles (London, Routledge)

Cohen, S. 1991. Rock Culture in Liverpool: Popular Music in the Making (Oxford, Clarendon Press)

Coulangeon, P., and Lemel, Y. 2007. 'Is 'distinction' really outdated? Questioning the meaning of the omnivorization of musical taste in contemporary France', Poetics, 35/2-3, pp. 93-111

Currid, B. 1995. 'We are family': house music and queer performativity', in Cruising the Performative: Interventions into the Repression of Ethnicity, Nationality and Sexuality, ed. S.E. Case, P. Brett and S. Foster (Bloomington, Indiana University Press), pp. 165-96

DeNora, T. 2000. Music in Everyday Life (Cambridge, Cambridge University Press)

Featherstone, M., and Hepworth, M. 1995. 'Images of positive aging: a case study of Retirement Choice Magazine', in Images of Aging: Cultural Representations of Later Life, ed. M. Featherstone and A. Wernick (London, Routledge)

Giddens, A. 1991. Modernity and Self Identity: Self and Society in the Late Modern Age (Cambridge, Polity)

Harrison, J., and Ryan, J. 2010. 'Musical taste and ageing', Ageing and Society, 30/4, pp. 649-69

Hays, T., and Minchiello, V. 2005. 'The meaning of music in the lives of older people: a qualitative study', Psychology of Music, 33/4, pp. 437-51

Hebdige, D. 1979. Subculture: The Meaning of Style (London, Routledge)

Hodkinson, P. 2011. 'Ageing in a spectacular "youth culture": continuity, change and community amongst older goths', British Journal of Sociology, 62/2, 262-82

Holbrook, M.B., and Schindler, R.M. 1989. 'Some exploratory findings on the development of musical tastes', Journal of Consumer Research, 16/1, pp. 119-24

Hughes, W. 1994. 'In the empire of the beat: discipline and disco', in Microphone Fiends: Youth Music and Youth Culture, ed. A. Ross and T. Rose (New York, Routledge), pp. 147-57

Koger, S., Chapin, K., and Brotons, M. 1999. 'Is music therapy an effective intervention for dementia? A meta-analytic review of literature', Journal of Music Therapy, 36/1, pp. 2-15

Kotarba, J.A. 2002. 'Baby boomer rock ' $\mathrm{n}$ ' roll fans and the becoming of self', in Postmodern Existential Sociology, ed. J.A. Kotarba and J.M. Johnson (Walnut Creek, Alta Mira), pp. 103-26

Lull, J. 1995. Media, Communication, Culture: A Global Approach (Cambridge, Polity Press)

Malbon, B. 1999. Clubbing: Dancing, Ecstasy and Vitality (London, Routledge)

Smith, N. 2009. 'Beyond the master narrative of youth: researching ageing popular music scenes', in The Ashgate Companion to Popular Musicology, ed. D.B. Scott (Surrey, Ashgate), pp. 427-45

Stevenson, N. 1995. Understanding Media Cultures (London, Sage) 
Taylor, J. 2008. 'The queerest of the queer: sexuality, politics and music on the Brisbane scene', Continuum: Journal of Media \& Cultural Studies, 22/5, pp. 647-61

Taylor, J. 2010. 'Queer temporalities: the significance of "music scene" participation in the social identities of middle-aged queers', Sociology, 44/5, pp. 893-907

Thornton, S. 1995. Club Cultures: Music, Media and Subcultural Capital (Cambridge, Polity)

Weinstein, D. 2000. Heavy Metal: The Music and its Culture, 2nd edn (New York, Da Capo) 